\title{
Virtual Screening and Molecular Docking for Arylalkylamine-N-Acetyltransferase (aaNAT) Inhibitors, a Key Enzyme of Aedes (Stegomyia) aegypti (L.) Metabolism
}

\author{
Bruno Luis Alves Lourenço1, Maicon Vinícius Araújo Santos Silva1, \\ Elisson Barros de Oliveira ${ }^{1}$, Wagner Rodrigues de Assis Soares ${ }^{1}$, \\ Aristóteles Góes-Neto ${ }^{2}$, Gesivaldo Santos ${ }^{3}$, Bruno Silva Andrade ${ }^{3}$ \\ ${ }^{1}$ Departamento de Saúde II, Universidade Estadual do Sudoeste da Bahia (UESB), Jequié, Brasil \\ ${ }^{2}$ Departamento de Ciências Biológicas, Universidade Estadual de Feira de Santana (UEFS), Feira de Santana, \\ Brasil \\ ${ }^{3}$ Departamento de Ciências Biológicas, Universidade Estadual do Sudoeste da Bahia (UESB), Jequié, Brasil \\ Email: bandrade@uesb.edu.br
}

Received 17 July 2015; accepted 20 September 2015; published 23 September 2015

Copyright (C) 2015 by authors and Scientific Research Publishing Inc.

This work is licensed under the Creative Commons Attribution International License (CC BY). http://creativecommons.org/licenses/by/4.0/

(c) (i) Open Access

\section{Abstract}

Background: Dengue is a Neglected tropical disease (NTDs) with high incidence in Brazil. This disease is caused by Dengue virus and is transmitted by Aedes aegypti mosquito. The search for new approaches for controlling of this disease is the subject of numerous studies. The aaNAT is a key enzyme in the metabolism of $A$. aegypti and is crucial in the sclerotization process, as well as regulation of circadian rhythm and inactivation of neurotransmitters. Computational techniques applied to studies of biological systems become an effective weapon in the mapping and management of 3D data structures, giving direction and guidance of potential ligands that can form stable complexes with targets of interest, using a Molecular Docking approach. The present study was conducted by a virtual screening, followed by docking calculations, in order to find molecules that could inhibit aaNAT. In this study, we used available compounds in SAM database (Bioinformatics and Medicinal Chemistry Laboratory-Southwest Bahia State University, Jequié-Bahia, Brazil), PubChem and ZINC. Results: The result of dockings with selected ligands showed good energy affinities, presenting potential inhibitory interactions with the enzyme active site. Conclusions: The Coa-S-acetyl-tryptamine and 3-indoleacriloil-coenzyme-A showed the same binding energies $\mathbf{- 8 . 9}$ $\mathrm{Kcal} / \mathrm{Mol}$ and were described as possible inhibitors of aaNAT.

How to cite this paper: Lourenço, B.L.A., Silva, M.V.A.S., de Oliveira, E.B., de Assis Soares, W.R., Góes-Neto, A., Santos, G. and Andrade, B.S. (2015) Virtual Screening and Molecular Docking for Arylalkylamine-N-Acetyltransferase (aaNAT) Inhibitors, a Key Enzyme of Aedes (Stegomyia) aegypti (L.) Metabolism. Computational Molecular Bioscience, 5, 35-44. 
Keywords

Aedes aegypti, aaNAT, Virtual Screening, Molecular Docking

\section{Introduction}

Neglected tropical diseases (NTDs) are responsible for most infections in poor countries [1]. Dengue is transmitted by Aedes (Stegomyia) aegypti (L.), and is one of the neglected diseases with the highest incidence in Brazil. This disease is caused by a RNA genome virus, and belonging to B group of arboviruses, genus flavivirus, family flaviviridae [1]. This virus has four immunologically distinct serotypes-DENV-1 to DENV-4. The first three are well known and documented in the Brazilian territory [2]-[4], and DENV-4 serotype is discovered recently [5].

Current strategies used to control mosquito and its larvae are based on techniques that integrate the reduction of reproduction sources and as addition of pitfalls [6] [7]. Other strategies include the use of Bacillus thuringiensis $\mathrm{H}-14$ (Bti) (biopesticide), as well as the chemical insecticides from classes of pyrethroids, carbamates, organophosphates, diflubenzuron and triflumuron [8] [9]. Furthermore, the use of vaccines against Dengue virus has not reached any effective protection [10] [11]. With this restriction, the need to develop methodologies for mosquito control, using computational strategies, which can suggest new chemical compounds for testing in vivo against $A$. aegypti, is crucial for the reduction of Dengue incidence in underdeveloped countries [12].

The arylalkylamine $\mathrm{N}$-acetyltransferase (aaNAT) is a key enzyme that promotes acetyl-CoA transacetilation to arylalkylamines [13] [14]. In mammals, aaNAT is primarily involved in the synthesis of N-acetylserotonin and melatonin. This process is dependent on the N-acetylation of serotonin (5-hydroxytryptamine) and it is a limiting step of the process that regulates the circadian rhythm in mammals [15] [16]. In insects, the aaNATs play multiple roles: in addition to melatonin synthesis, aaNAT is involved in the inactivation of aromatic neurotransmitters and is essential in the cuticle sclerotization [17]. The aaNATs inactivate arylalkylamines such as octopamine, dopamine, and serotonin [18] [19] since insects have no monoamine oxidase (MAO) [20] [21].

The cuticular exoskeleton gives the insect a rigid layer and prevents direct contact with the external environment, avoiding infections and injury. This structure is important for the mechanical support and flexibility. During its lifetime, the mosquito periodically exchanges the old cuticle and produces a new one [22]. In developing this new cuticle, insects undergo a process called sclerotization, where it is hard and darkened. Because it is important for vector survival, the use of a key enzyme in cuticle formation is a good way to block A. aegypti development [22] [23]. There are two sclerotization precursors: $\mathrm{N}$-acetyldopamine and $\mathrm{N}-\beta$-alanyldopamine. The first one is an aaNAT product and shows that this enzyme holds a special place in the insect cuticle sclerotization [24] [25].

Molecular Docking studies allow us to analyze the orientation of the molecule (ligand/inhibitor), describing the affinity of a given molecule to a protein-binding site [26]. Virtual screening of chemicals is one of the main techniques currently used in Drug Discovery, testing natural and synthesized compounds [27] [28]. Online databases and cheminformatics tools, such as ZINC [29] and SEA [30], respectively, allow comparison between previous used compounds and millions of deposited structures.

The aim of this study is to perform a virtual screening for new potential inhibitors, selected from online databases that can form complexes with aaNAT from A. aegypti, using molecular docking approach.

\section{Ease of Materials and Methods}

The crystal structure of aaNAT was obtained from Protein Data Bank (www.pdb.org) [31], with the code 1L0C. We used PyMOL 1.7.4.4 [32] to check the protein about possible structure crashes and the positions of amino acids from active site. Then the protein was used for docking studies.

\subsection{Ligand Searching}

Based on literature review that used in vivo tests against A. aegypti, we created a list of ligands previously described as aaNAT inhibitors. Then, we used these structures in order to search similar structures, based on a mini- 
mum tanimoto coefficient of 0.7, in the public ligand databases: PubChem (http://pubchem.ncbi.nlm.nih.gov) and ZINC (https://zinc.docking.org/). Additionally, we used our intranet database from compounds isolated from Brazilian plants (SAM Database-Bioinformatics and Medicinal Chemistry Laboratory—Southwest Bahia State University, Jequié-Bahia, Brazil). Using a 70\% cut-off similarity between query (known) and deposited structures, we saved the results in mol2 format to use in docking process.

\subsection{Molecular Docking}

Molecular Docking process was performed by AutoDock Vina [33]. The ligand and receptor (1L0C) were prepared using AutoDockTools 1.5.6 [33]. All hydrogen atoms were added to ligands and receptor, in order to compute the protonation of input structures. The grid box, which indicates the receptor-binding pocket, was adjusted to the active site of aaNAT. Box position was determined according to previous described aaNAT crystallographic structure [13] [19] [24] [34]-[36], and a configuration file was generated considering the box size and coordinates on the receptor. For each screened ligand we added all hydrogen and possible molecular torsions [33]. Receptor and ligands structures were saved in pdbqt format, in order to calculate docking energy affinities (Kcal/Mol). AutoDock Vina generated energy affinity values for nine different docking poses, for each ligand, inside aaNAT active site.

AutoDock Vina results were analyzed for each calculation to obtain the affinity energies of each complex, according to the conformation of the ligand in the aaNAT active site, considering the RMSD between initial and subsequent structures. We used the PyMOL 1.7.4.4, LigandScout 3.1 [37] and Discovery Studio 3.5 [38] to check the number of hydrogen bonds and non-covalent interactions for each complex, and for generating figures the complexes and interaction maps.

\section{Results and Discussion}

After ligand searching and comparison in ZINC, PubChem, and SAM databases, we selected three compounds (Figure 1), which could interact with aaNAT. Docking poses, affinity energies, as well as Hydrogen bond acceptor ( $\mathrm{HbA}$ ) and Hydrogen bond donor (HbD) information about each molecule in the complex are shown in Table 1. Coa-S-acetyltryptamine (CoASAT) is the molecule that reaches best affinity energy and $\mathrm{HbA} / \mathrm{HbD}$ characteristics, followed by 3-indoleacriloil-coenzyme, and 3-coenzyme-A indolepropionil with lowest energy.

The biochemical activity of aaNAT is closely associated to inactivation of neurotransmitters. This possibility is supported by the fact that (1) capacity of acetylating various neurotransmitters/arylalkylamines; (2) the N-acetildopamine was found in the head of the mosquito fed dopamine; (3) these genes are expressed in the mosquito's head [39]. An accumulation of neurotransmitters like dopamine in the synaptic cleft can cause various damages, since Aedes aegypti have no monoamine oxidase A and B (MAOA and MAOB), the most important inactivators of neurotransmitters [39] and this prolonged signaling may be fatal.

Blocking aaNAT, the cuticle formation process is impaired, and it will affect the development of the adult mosquito, since this is essential for joint motion, mechanical support, and protects it from external environment, and rust infections. There is also the excessive burning of neurotransmitters in the synaptic cleft, since they use aaNAT to inactivate neurotransmitters. Two studies with Bombyx mori (silkworm) showed that loss of aaNAT function results in the formation of a cuticle with strong dark staining [39], confirming that there is an intimate involvement of aaNAT with cuticle formation.

The representation of the ligands interacting with the active site of aaNAT is shown in Figure 2. It is noted that all ligands interact in the same active site than the crystallographic inhibitor (CoASAT) [40].

Table 1. Docking results and $\mathrm{HbA} / \mathrm{HbD}$ features of the ligands used in the docking with aaNAT.

\begin{tabular}{cccc}
\hline Molecule & \multicolumn{3}{c}{ Docking Results } \\
\cline { 2 - 4 } CoA-S-scetyl tryptamine & Affinity (Kcal/Mol) & Hydrogen Bond Donor & Hydrogen Acceptor \\
3-indoleacriloil-CoA & -8.9 & 11 & 22 \\
3-indolepropionil-CoA & -8.9 & 10 & 22 \\
\hline
\end{tabular}



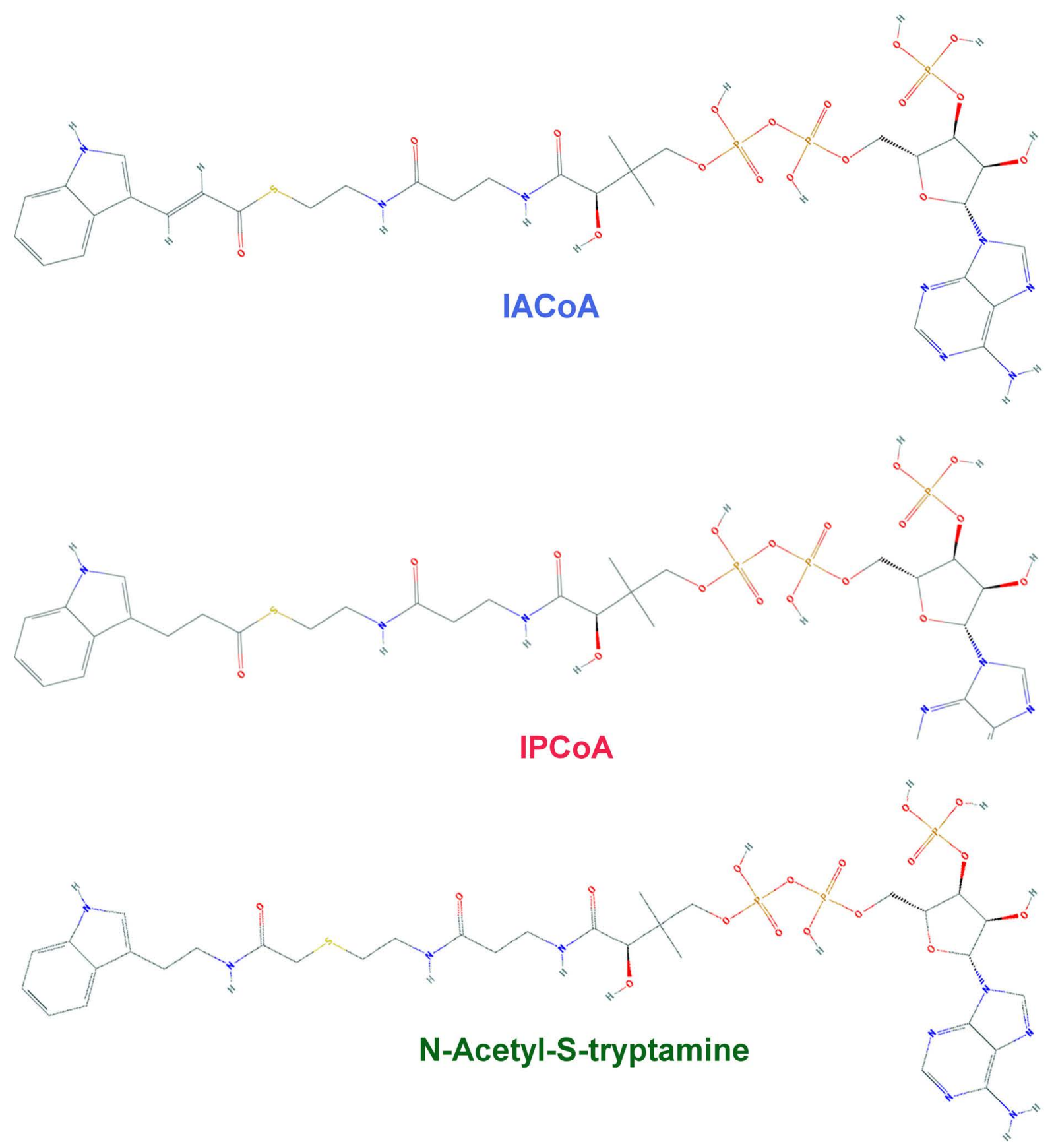

Figure 1. 2D structures of ligands used on virtual screening with aaNAT.

\subsection{Complex 1L0C-CoA-S-Acetyltryptamine (CoASAT)}

After docking calculations, CoASAT appears within the hydrophobic pocket of 1L0C. The interaction is covering almost all aaNAT active site, as illustrated in Figure 3.

The interaction map (Figure 4) clearly shows the interaction between the amino acids of aaNAT with s-acetyl CoA tryptamine. The aaNAT binding site is composed by Tyr168, His120 and His122 [39], but there are other amino acids that appear next the active site and form other interactions, such as Leu164, Leu124, Arg170, Phe167, Ala125, Arg131, Val126, and Glu161. Van der Waals and Electrostatic forces form complex 1L0C-CoASAT, in its majority, but hydrogen interactions are formed in the region close to the active site, with Leu164, Arg170, and Phe167. 


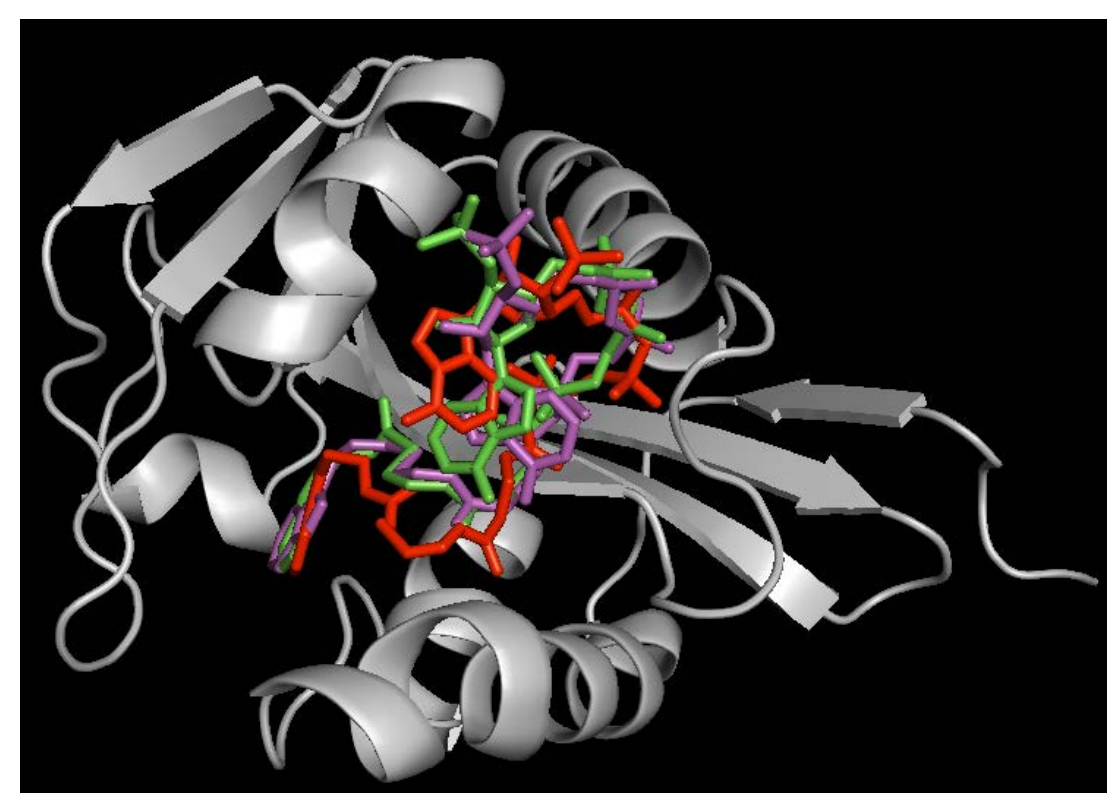

Figure 2. Ligand superposition inside aaNAT active site. Green: IACoA; Magenta: IPCoA; and Red: CoASAT.

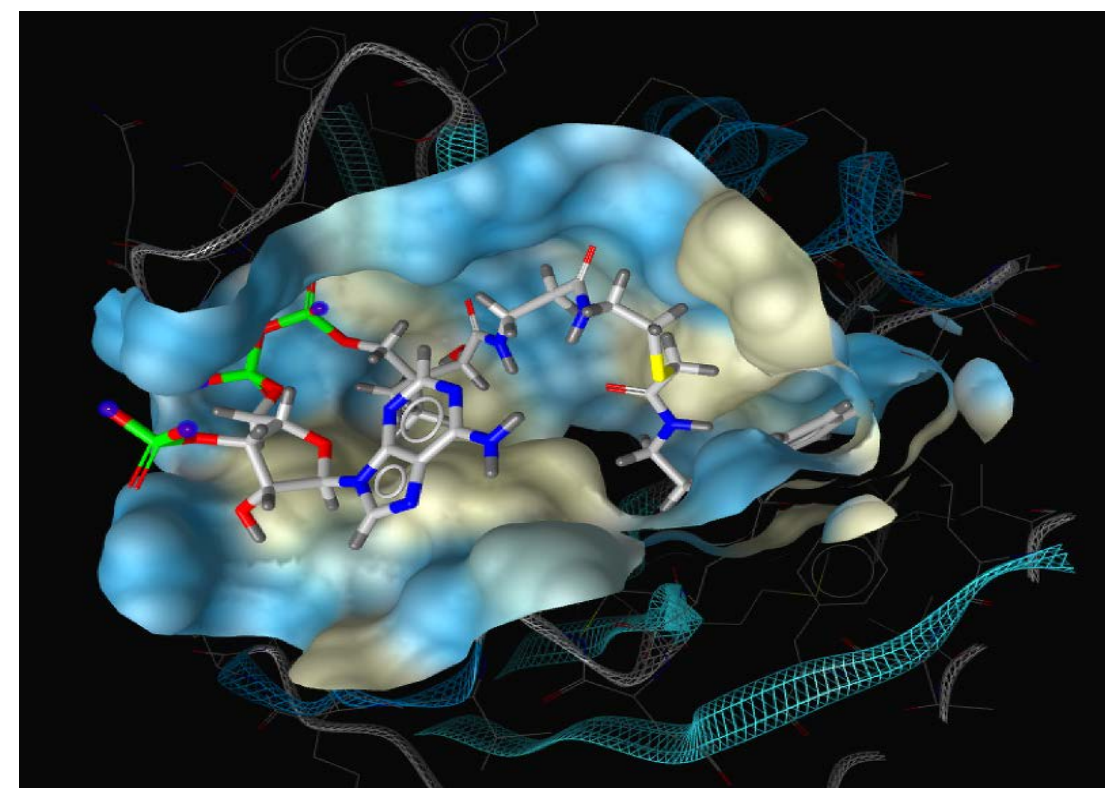

Figure 3. Complex between CoASAT and aaNAT. The ligand appears inside the hydrophobic pocket of the enzyme.

\subsection{Complex 1L0C-3-Indoleacriloil-Coenzyme A (IACoA)}

In the complex 1L0C-IACoA (Figure 5), the interaction map (Figure 6) shows 3-indoleacriloil-coenzyme A in the same active site of CoASAT. We observed that indoleacriloil 3-coenzyme A has a different torsion, in comparison to CoA-S-acetyl tryptamine, and this condition facilitates their entry into the active site of the enzyme. The great number of interactions occurs the aaNAT binding pocket with amino acids Arg170, Phe167, Phe168, Ala163, Ala125, Leu164, Leu124, and Val126. The complex is stabilized with Electrostatic and Van der Waals forces, as well as hydrogen interactions.

\subsection{Complex 1L0C-3-Indolepropionil-Coenzyme A (IPCoA)}

This complex aaNAT-IPCoA (Figure 7) presented lowest affinity energy, but in comparison with other proposed 
ligands this molecules showed interactions with the active pocket amino acids of the enzyme (Figure 8). The complex is mainly stabilized by Electrostatic and Van der Waals interactions, and also by hydrogen bonds with Ser137, Arg170, Gln133, Gly134, Leu160 and Lys135.

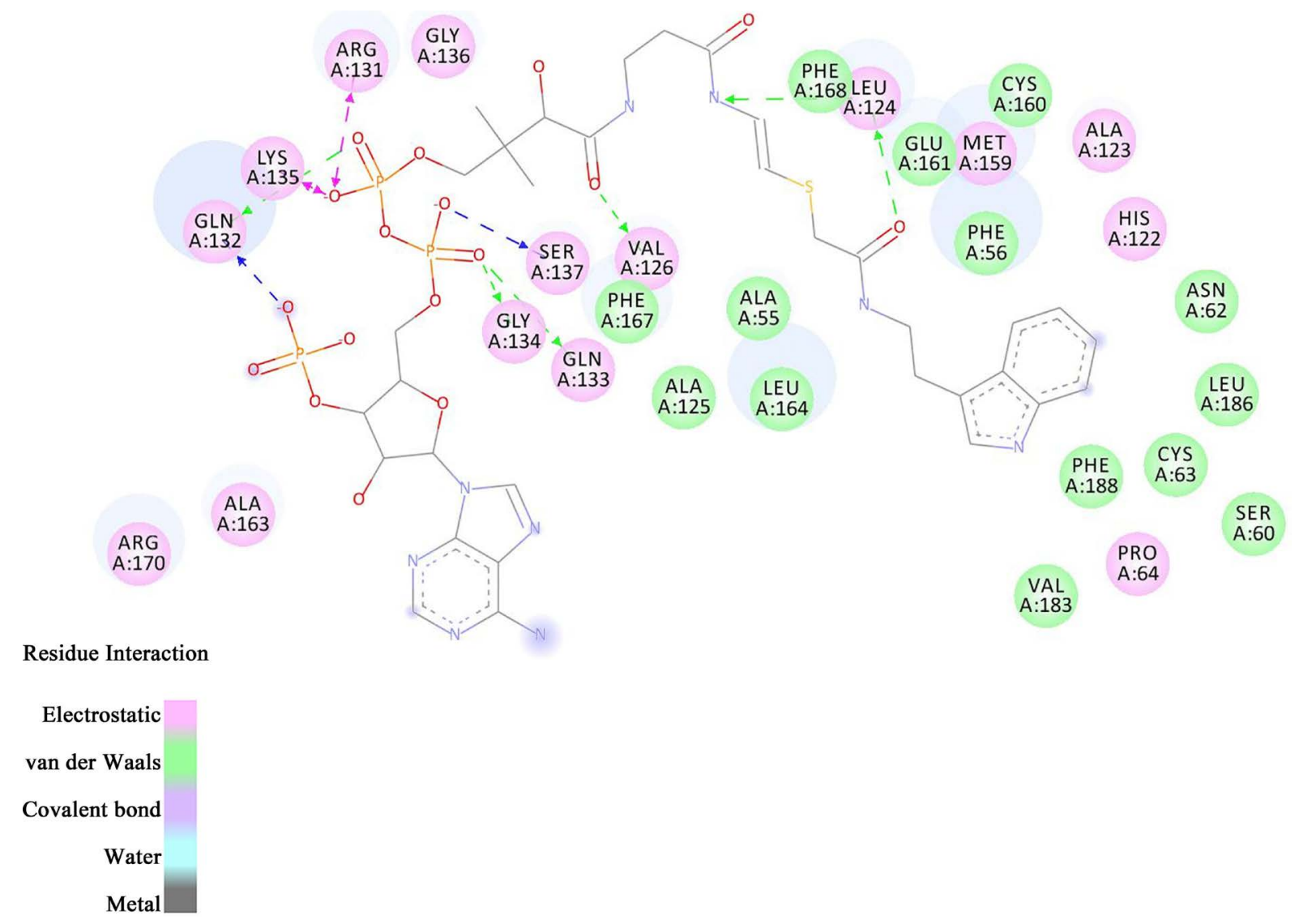

Figure 4. Interaction map, showing amino acids from active site of aaNAT interacting with the ligand CoASAT.

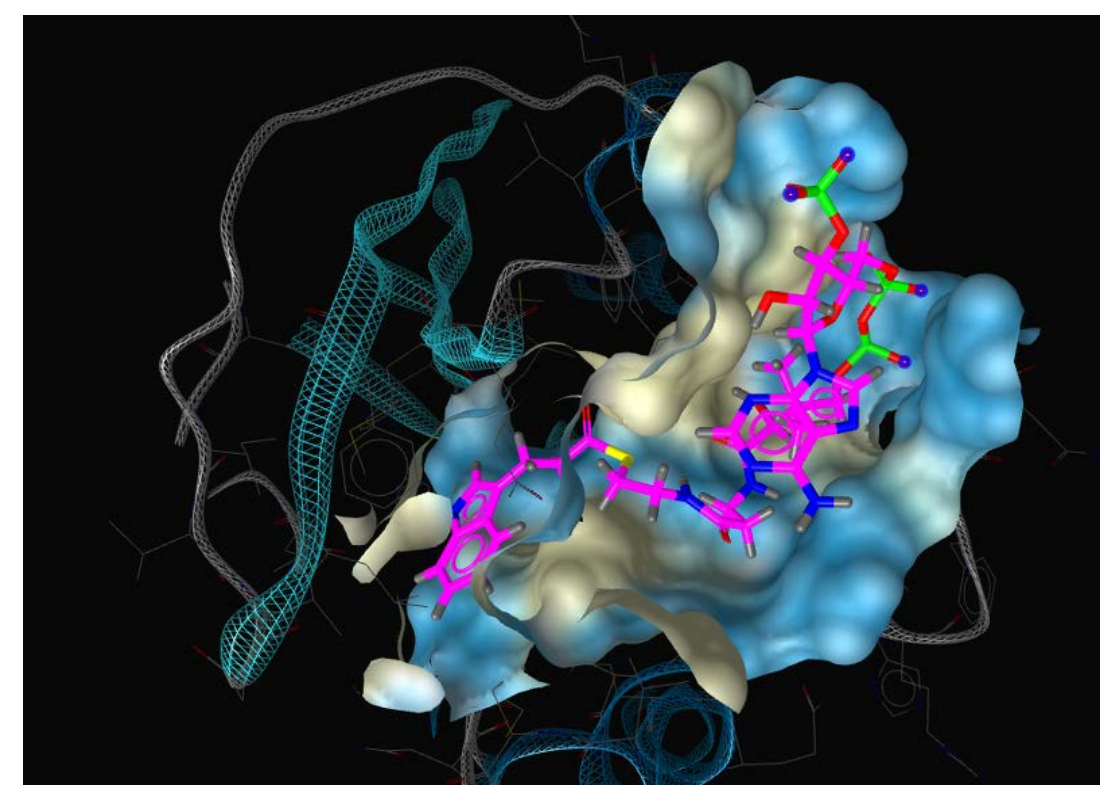

Figure 5. Complex between IACoA and aaNAT. The ligand appears in the region of active site. 


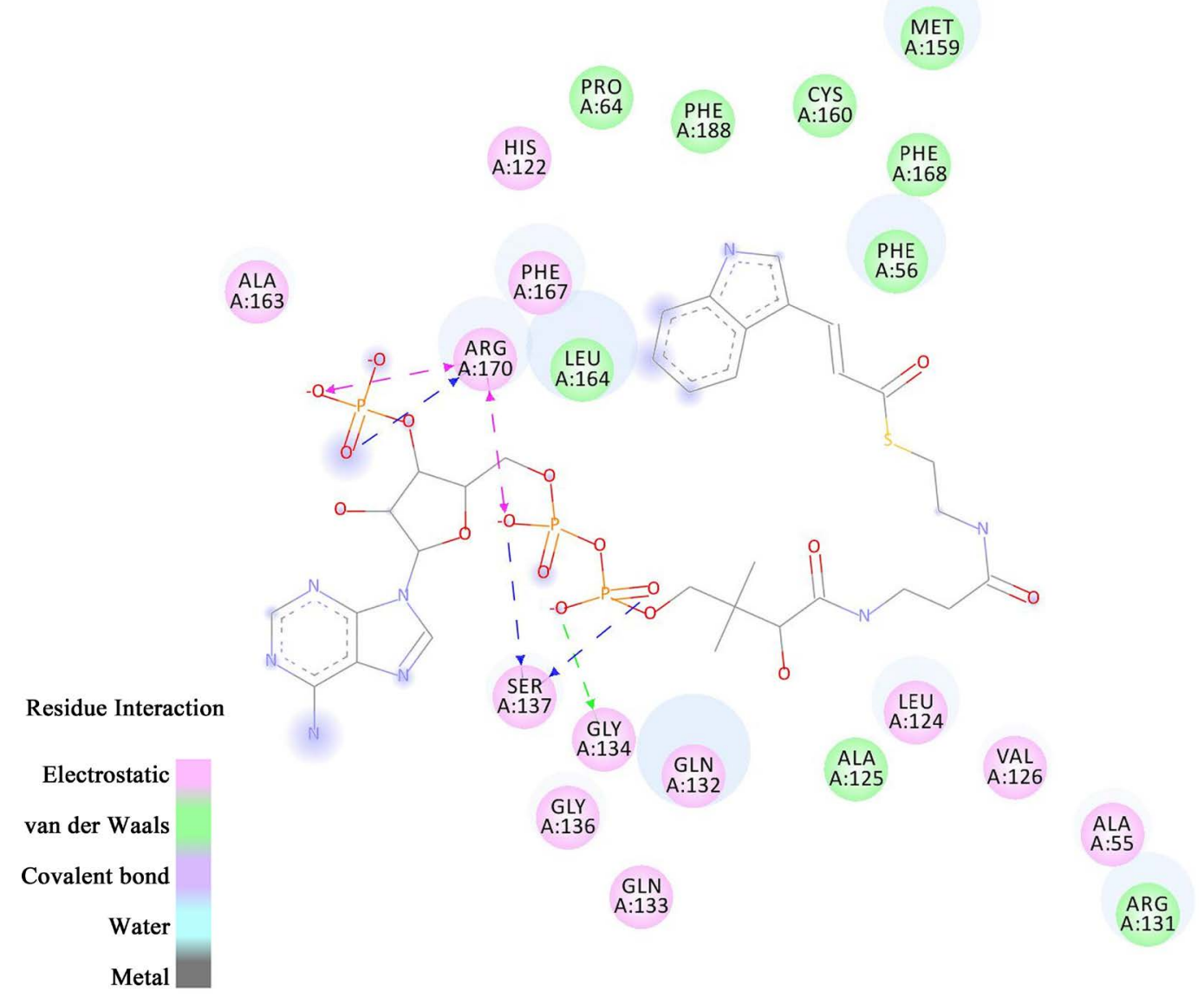

Figure 6. Interaction map, showing amino acids from active site of aaNAT interacting with the ligand IACoA.

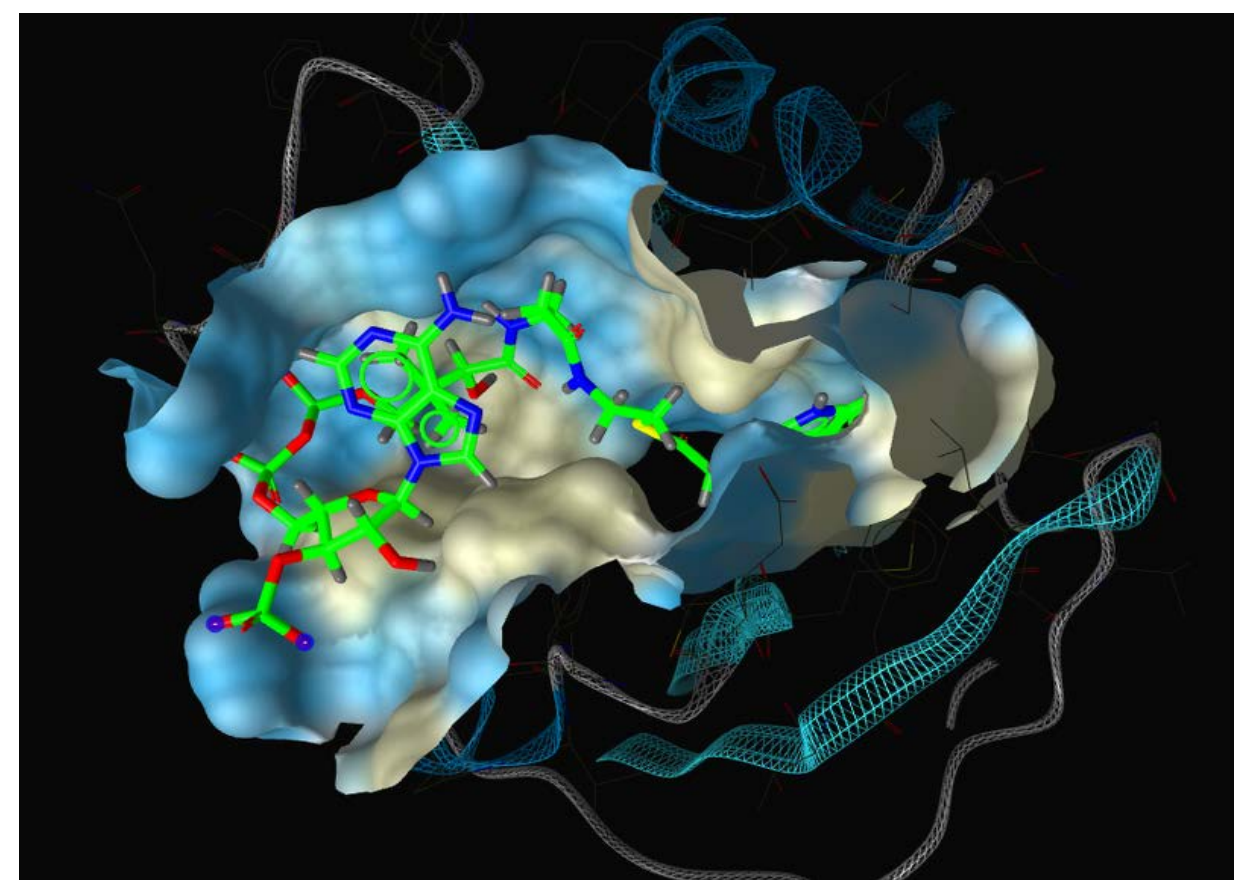

Figure 7. Complex between IPCoA and aaNAT. The ligand appears in the region of active site. 

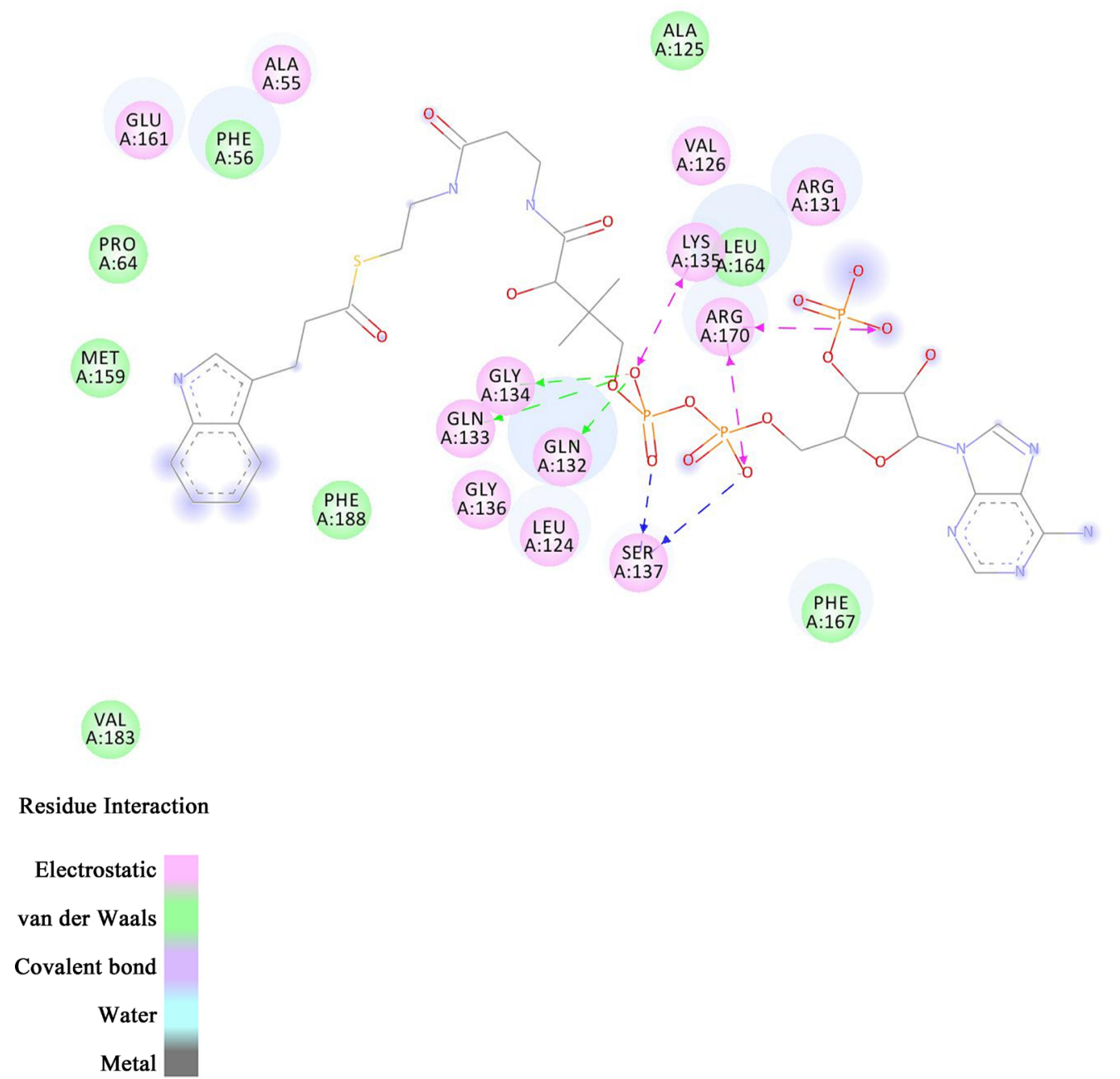

Figure 8. Interaction map, showing amino acids from active site of aaNAT interacting with the ligand IPCoA.

\section{Conclusions}

The Aedes aegypti is still a target of numerous health campaigns in Brazil, in order to reduce Dengue contamination. The use of Cheminformatics and Structural Biology is strongly valid to propose new chemical structures that interact with some key metabolism enzymes of this mosquito.

This study used the aaNAT, a catalytic enzyme with great importance in the lifecycle of A. aegypti. Using a known inhibitor and accessing online molecules databases, it was possible to reach some analogues that could be used as new inhibitors.

Results showed that CoASAT $(-8.9 \mathrm{kcal} / \mathrm{mol})$ and IACoA $(-8.9 \mathrm{kcal} / \mathrm{mol})$ have a better interaction with the target, considering energy affinity and number of interactions with the amino acids from aaNAT active site, while 3-indolepropionyl coenzyme A showed the smallest affinity energy as well as number of interactions in the active site. In addition, we suggest these compounds to be tested in vivo against larvae and adult A. aegypti.

\section{Acknowledgements}

We would like to thank FAPESB for providing undergraduate student scholarships and financial help to this study.

\section{Competing Interests}

The authors declare that they have no competing interests. 


\section{Authors' Contributions}

BL: Virtual Screening, Docking and write the manuscript; MS: Virtual Screening; EO: Generated interaction maps; WS: Write manuscript; AGN: Write manuscript, revise English; GS: Write manuscript; BA: Virtual Screening, Docking, generated interaction maps, write the manuscript and supervised the study.

\section{References}

[1] Hotez, P.J., Fenwick, A., Savioli, L and, Molyneux, D.H. (2009) Rescuing the "Bottom Billion” through Neglected Tropical Disease Control. The Lancet, 373, 1570-1574. http://dx.doi.org/10.1016/S0140-6736(09)60233-6

[2] San Martín, J.L., Brathwaite, O., Zambrano, B., Solórzano, J.O., Bouckenooghe, A., Dayan, G.H., et al. (2010) The Epidemiology of Dengue in the Americas over the Last Three Decades: A Worrisome Reality. American Journal of Tropical Medicine and Hygiene, 82, 128-135. http://dx.doi.org/10.4269/ajtmh.2010.09-0346

[3] Teixeira, M.G., Costa, M.C.N., Barreto, F. and Barreto, M.L. (2009) Dengue: Vinte e cinco anos da reemergência no Brasil. Cadernos de Saúde Pública, 25, S7-S18.

[4] World Health Organization (2009) Dengue: Guidelines for Diagnosis, Treatment, Prevention, and Control. Special Programme for Research and Training in Tropical Diseases. World Health Organization, Geneva.

[5] Nogueira, R.M.R. and Eppinghaus, A.L.F. (2011) Dengue Virus Type 4 Arrives in the State of Rio. de Janeiro: A Challenge for Epidemiological Surveillance and Control. Memórias do Instituto Oswaldo Cruz, 106, 255-256. http://dx.doi.org/10.1590/S0074-02762011000300001

[6] Coelho, A.A.M., De Paula, J.E. and Espindola, L.S. (2009) Atividade larvicida de extrato vegetais sobre Aedes aegypti (L.) (Diptera:Culicidae), condições de laboratório. Bioassay, 4, 1-6. http://dx.doi.org/10.14295/BA.v4.0.22

[7] Rose, R.I. (2001) Pesticides and Public Health: Integrated Methods of Mosquito Management. Emerging Infectious Diseases, 7, 17-23. http://dx.doi.org/10.3201/eid0701.010103

[8] Braga, I.A. and Valle, D. (2007) Aedes aegypti: inseticidas, mecanismos de ação e resistência. Epidemiologia e Serviços de Saúde, 16, 279-293. http://dx.doi.org/10.5123/s1679-49742007000400006

[9] Lefevre, A.M.C., Lefevre, F., Scandar, S.A.S, Yasumaro, S. and Sampaio, S.M.P. (2003) Representações dos agentes de combate ao Aedes aegypti sobre a estratégia de retirada do inseticida nas ações de controle do vetor. Revista Brasileira de Epidemiologia, 6, 359. http://dx.doi.org/10.1590/S1415-790X2003000400010

[10] Coller, B.A.G. and Clements, D.E. (2011) Dengue Vaccines: Progress and Challenges. Current Opinion in Immunology, 23, 391. http://dx.doi.org/10.1016/j.coi.2011.03.005

[11] Jardim, J.B. and Schall, V.T. (2009) Prevenção da dengue: A proficiência em foco. Cadernos de Saúde Pública, 25, 2529-2530. http://dx.doi.org/10.1590/S0102-311X2009001100023

[12] Garcez, W.S., Garcez, F.R., Silva, L.M.G.E. and Sarmento, U.C. (2013) Substâncias de Origem Vegetal com Atividade Larvicida Contra Aedes aegypti. Revista Virtual de Química, 5, 363-393.

[13] Mehere, P., Han, Q., Christensen, B.M. and Li, J.Y. (2011) Identification and Characterization of Two Arylalkylamine $N$-Acetyltransferases in the Yellow Fever Mosquito, Aedes aegypti. Insect Biochemistry and Molecular Biology, 41, 707-714. http://dx.doi.org/10.1016/j.ibmb.2011.05.002

[14] Evans, D.A. (1989) N-Acetyltransferase. Pharmacology \& Therapeutics, 42, 157-234. http://dx.doi.org/10.1016/0163-7258(89)90036-3

[15] Klein, D.C. (2007) Arylalkylamine N-Acetyltransferase: “The Timezyme”. The Journal of Biological Chemistry, 282, 4233-4237. http://dx.doi.org/10.1074/jbc.R600036200

[16] Klein, D.C. (2006) Evolution of the Vertebrate Pineal Gland: The aaNAT Hypothesis. Chronobiology International, 23, 5-20. http://dx.doi.org/10.1080/07420520500545839

[17] Smith, T.J. (1990) Phylogenetic Distribution and Function of Arylalkylamine N-Acetyltransferase. BioEssays, 12, 3033. http://dx.doi.org/10.1002/bies.950120107

[18] Amherd, R., Hintermann, E., Walz, D., Affolter, M. and Meyer, U.A. (2000) Purification, Cloning, and Characterization of a Second Arylalkylamine $N$-Acetyltransferase from Drosophila melanogaster. DNA and Cell Biology, 19, 697705. http://dx.doi.org/10.1089/10445490050199081

[19] Brodbeck, D., Amherd, R., Callaerts, P., Hintermann, E., Meyer, U.A. and Affolter, M. (1998) Molecular and Biochemical Characterization of the aaNAT1 (Dat) Locus in Drosophila melanogaster: Differential Expression of Two Gene Products. DNA and Cell Biology, 17, 621-633. http://dx.doi.org/10.1089/dna.1998.17.621

[20] Bortolato, M., Chen, K. and Shih, J.C. (2008) Monoamine Oxidase Inactivation: From Pathophysiology to Therapeutics. Advanced Drug Delivery Reviews, 60, 1527-1533. http://dx.doi.org/10.1016/j.addr.2008.06.002 
[21] Tsugehara, T., Iwai, S., Fujiwara, Y., Mita, K. and Takeda, M. (2007) Cloning and Characterization of Insect Arylalkylamine $N$-Acetyltransferase from Bombyx mori. Comparative Biochemistry and Physiology Part B: Biochemistry and Molecular Biology, 147, 358-366. http://dx.doi.org/10.1016/j.cbpb.2006.10.112

[22] Sheng, J.Z., An, K., Deng, C.S., Li, W.J., Bao, X.M. and Qiu, D.W. (2006) Cloning a Cuticle-Degrading Serine Protease Gene with Biologic Control Function from Beauveria brongniartii and Its Expression in Escherichia coli. Current Microbiology, 53, 124-128. http://dx.doi.org/10.1007/s00284-005-5336-5

[23] Luz, C. and Batagin, I. (2005) Potential of Oil-Based Formulations of Beauveria bassiana to Control Triatoma infestans. Mycopathologia, 160, 51-62. http://dx.doi.org/10.1007/s11046-005-0210-3

[24] Andersen, S.O. (2010) Insect Cuticular Sclerotization: A Review. Insect Biochemistry and Molecular Biology, 40, 166178. http://dx.doi.org/10.1016/j.ibmb.2009.10.007

[25] Han, Q., Ding, H.Z., Robinson, H., Christensen, B.M. and Li, J.Y. (2010) Crystal Structure and Substrate Specificity of Drosophila 3,4-Dihydroxyphenylalanine Decarboxylase. PLOS ONE, 5, e8826. http://dx.doi.org/10.1371/journal.pone.0008826

[26] Kitchen, D.B., Decornez, H., Furr, J.R. and Bajorath, J. (2004) Docking and Scoring in Virtual Screening for Drug Discovery: Methods and Applications. Nature Reviews Drug Discovery, 3, 935-949. http://dx.doi.org/10.1038/nrd1549

[27] Kroemer, R.T. (2007) Structure-Based Drug Design: Docking and Scoring. Current Protein \& Peptide Science, 8, 312328. http://dx.doi.org/10.2174/138920307781369382

[28] Klebe, G. (2004) Lead Identification in Post-Genomics: Computers as a Complementary Alternative. Drug Discovery Today: Technologies, 1, 225-230. http://dx.doi.org/10.1016/j.ddtec.2004.10.010

[29] Irwin, J.J. and Shoichet, B.K. (2005) ZINC-A Free Database of Commercially Available Compounds for Virtual Screening. Journal of Chemical Information and Modeling, 45, 177-182. http://dx.doi.org/10.1021/ci049714+

[30] Keiser, M.J., Roth, B.L., Armbruster, B.N., Ernsberger, P., Irwin, J.J. and Shoichet, B.K. (2007) Relating Protein Pharmacology by Ligand Chemistry. Nature Biotechnology, 25, 197-206. http://dx.doi.org/10.1038/nbt1284

[31] Berman, H.M., Bhat, T.N., Bourne, P.E., Feng, Z.K., Gilliland, G., Weissig, H. and Westbrook, J. (2000) The Protein Data Bank and the Challenge of Structural Genomics. Nature Structural \& Molecular Biology, 7, 957-959. http://dx.doi.org/10.1038/80734

[32] Schrodinger, L. (2010) The PyMOL Molecular Graphics System, Version 1.3r1.

[33] Trott, O. and Olson, A.J. (2010) AutoDock Vina: Improving the Speed and Accuracy of Docking with a New Scoring Function, Efficient Optimization, and Multithreading. Journal of Computational Chemistry, 31, 455-461.

[34] Andersen, S.O. (2008) Quantitative Determination of Catecholic Degradation Products from Insect Sclerotized Cuticles. Insect Biochemistry and Molecular Biology, 38, 877-882. http://dx.doi.org/10.1016/j.ibmb.2008.06.003

[35] Dai, F.Y., Qiao, L., Tong, X.L., Cao, C., Chen, P., Chen, J., et al. (2010) Mutations of an Arylalkylamine-N-Acetyltransferase, Bm-iaaNAT, Are Responsible for Silkworm Melanism Mutant. The Journal of Biological Chemistry, 285, 19553-19560. http://dx.doi.org/10.1074/jbc.M109.096743

[36] Neckameyer, W.S., Holt, B. and Paradowski, T.J. (2005) Biochemical Conservation of Recombinant Drosophila Tyrosine Hydroxylase with Its Mammalian Cognates. Biochemical Genetics, 43, 425-443. http://dx.doi.org/10.1007/s10528-005-6781-3

[37] Wolber, G. and Langer, T. (2005) LigandScout: 3-D Pharmacophores Derived from Protein-Bound Ligands and Their Use as Virtual Screening Filters. Journal of Chemical Information and Modeling, 45, 160-169. http://dx.doi.org/10.1021/ci049885e

[38] Accelrys Software Inc. (2009) Discovery Studio Modeling Environment, Release 2.5. Accelrys Software Inc., San Diego.

[39] Zhan, S., Guo, Q.H., Li, M.H., Li, M.W., Li, J.Y., Miao, X.X. and Huang, Y.P. (2010) Disruption of an N-Acetyltransferase Gene in the Silkworm Reveals a Novel Role in Pigmentation. Development, 137, 4083-4090. http://dx.doi.org/10.1242/dev.053678

[40] Scheibner, K.A., De Angelis, J., Burley, S.K. and Cole, P.A. (2002) Investigation of the Roles of Catalytic Residues in Serotonin $N$-Acetyltransferase. The Journal of Biological Chemistry, 277, 18118-18126.

http://dx.doi.org/10.1074/jbc.M200595200 